\title{
Assessing Punctuation Errors Made by Secondary School Students in English Language Comprehension in Ogun State, Nigeria
}

\author{
B. Oluwakemi Adekola ${ }^{1, *} \&$ Oluseun Fatai Lawal ${ }^{2}$ \\ ${ }^{1}$ Department of Arts \& Social Sciences Education (Assed), Faculty of Education, Olabisi Onabanjo University, \\ Ago-Iwoye, Ogun State, Nigeria \\ ${ }^{2}$ Institute of Education, Faculty of Education, Olabisi Onabanjo University, Ago-Iwoye, Ogun State, Nigeria \\ *Correspondence: Department of Arts \& Social Sciences Education (Assed), Faculty of Education, Olabisi Onabanjo \\ University, Ago-Iwoye, Ogun State, Nigeria. E-mail: Kemiadekola@Gmail.Com
}

Received: April 10, 2017

Accepted: May 8, 2017 Online Published: July 25, 2017

doi:10.5430/ijelt.v4n2p39

URL: https://doi.org/10.5430/ijelt.v4n2p39

\begin{abstract}
This study assessed the errors in English comprehension by Senior Secondary School Students. Errors in English punctuation in this study were categorized as mechanical errors in comprehension with particular emphasis on punctuation marks and spelling. This study adopted a descriptive research design of ex-post-facto type. The target groups for the study were Ogun State Secondary Schools in Nigeria. The samples were drawn from four (4) geo-political zones in Ogun State of Nigeria (Ijebu, Remo, Yewa and Egba). Multi-stage stratified sampling technique was used to select five co-educational Secondary Schools from the four geo-political zones. Five schools were selected with fifty (50) Secondary Students III (SSS 3) per school totaling two hundred and fifty (250) male and female students in each of the divisions. Two instruments, Errors in English Language Comprehension (EELC), and an achievement test in English Language Punctuation (ATELP) were used to collect data from the one thousand (1000) students who were randomly sampled as participants. The validity and reliability of the instrument were determined by trial testing. The data were subjected to Chi-square, Analysis of Variance (ANOVA) and Pearson Product Moment Correlation coefficient. The data were tested for significance at the 0.05 level. Based on the findings, it was detected that students made more errors in punctuation than in spellings. This could be attributed to lack of knowledge and understanding of common mistakes made in English. Part of the recommendations made was that; teachers should concentrate on areas of difficulties such as comma, colon and semi-colon for students.
\end{abstract}

Keywords: comprehension, punctuation, reading and writing, spelling errors

\section{Introduction}

The place of reading in the world today cannot be over emphasized. The world is becoming a global village by the reason of high technological advancements. Reading remains the sure way of acquainting ourselves with global realities. Learning a language involves becoming proficient in the four language skills of speaking, listening, reading and writing. The effectiveness of student's performance in language performance centers on the mastery of the four basic language skills, it is therefore expected that specific emphasis is placed on the learning of these skills by both educators and students.

Errors are inevitable part in the language learning process and neither the teacher nor students is free from making errors. It is useful to have an understanding of the variety of typical errors in reading and writing. Largely, errors are unavoidable but also amenable to corrections(Jiboku, 2003). Mechanical errors are those of orthography (spelling and capitalization) and punctuation. English spelling may be difficult, but it is possible to overcome those difficulties with diligent use of a dictionary and computer spell-check. Every writer should eradicate all or almost all the spelling errors in a piece of writing.

Research has shown that proper language use entails proper manipulation of the skills because they play crucial roles in human learning and intellectual activities: 
i. Reading is an essential key to success in our society. The ability to read and write is highly valued and important for social and economic empowerment. Good readers and writers connect and utilize ideas and information from a variety of previous life and literary experiences(Jiboku, 2003).

ii. Reading and writing are factors for individuals and the development of a nation.

iii. Reading and writing are seen as the fundamental components of primary and secondary school curricular. Students' success depends on the extent to which they can obtain and write information from print, quickly and efficiently.(Oladunjoye, 2008)

Through reading and writing, students observe writings such as symbols, letters, words, phrases and sentences; persons, pictures, signs, characters, works of art, making interpretations and judgments on such things or persons and window through which a literate person can see the world far above his physical reach.(Otenaike, 2005)

\section{Statement of the Problem}

In Nigeria today, it is appalling that the level of reading and writing skills are very low despite the increasing volumes of reading materials that are readily available. Products of our schools are found to be deficient in their reading and writing skills as their performances in the two skills are at variance with the other two skills of listening and speaking(Adenuga, 2015). The divergence between the expected and observed learning outcomes/ behaviours is attributed to the status of English as a second language in Nigeria.

A study(Otenaike, 2005) revealed that the reading rate of Nigerians is very poor. This trend seems to negatively affect writing pattern in the country. Most students only read and write because they need to pass examinations not minding the mechanical errors like spellings and punctuation. It is challenging to learn English as a language in Nigeria, as mechanical errors slow down students' reading achievements.

There seems to be strong connection between difficulties faced as a result of disability in reading and writing. Such problems can be traced to early delays in receptive and expressive language development. Among students who are diagnosed with learning errors, $80 \%$ are diagnosed to have their reading and writing skills lagging behind; $90 \%$ are identified to have reading and writing as their primary difficulties Reading and writing comprehension section of the English language examination is an obstacle against Nigerian learners' struggle towards academic success. This is because of the bilingual nature of the child and poor socio-economic background, among other unfavorable environmental factors.( Awodele, 2003)

The Chief Examiner's reports of the SSCE shed light on the poor performance of candidates in English Language. The reports showed that many of the weakness observed in the scripts of the candidates have to do with insufficient exposure to reading and writing. The reports regard "expression" as a very big problem. Among other things, the reports exposed the problems as follows:

1. Most of the candidates cannot read and write acceptable English sentences. The problem is not only grammatical but also semantics.

2. There is a general lack of sensibility to idioms of English, resulting in several un-English collocations.

3. In addition to the above, mechanical accuracy has not improved. Over $90 \%$ of the essays had zero in this aspect.

4. Students need to be careful with spelling, punctuation, concord etc.

5. Many compositions were seriously marred by poor spelling, poor punctuation and faulty grammar.

6. It is disappointing that after six years of secondary education, many candidates demonstrated ignorance of correct use of comma, the full stop and question mark.

7. Equally disappointing is the fact that they misspelt the common words that constitute their vocabulary for daily communication both at home and in the school. To make the matter worse is now the use of social media words.

\subsection{What is a Punctuation Mark?}

Punctuation mark is the use of conventional signs and certain typographical devices as aids to the understanding of handwritten and printed texts. In written texts, punctuation is vital to disambiguate the meaning of sentences. The rules of punctuation vary with language, location, register and time. Punctuation is constantly evolving, hence, certain aspects of punctuation are stylistic and are thus the author's choice. 


\subsection{Punctuation Marks}

There are 14 punctuation marks commonly used in British and American English. They are: full-stop, question mark, exclamation point, comma, semicolon, colon, dash, hyphen, parentheses, brackets, braces, apostrophe, quotation marks and ellipses.

Comma (,): It is used to show separation of ideas or elements within the structure of a sentence. It is also used in letter writing after the salutation and closing.

Semi-colon (;): It is used to connect independent clauses, it shows a closer relationship between the clauses than a period would show e.g. Kemi was hurt; he knew she only said it to upset him.

Colon (:): It has two main uses. The $1^{\text {st }}$ is after a word introducing a quotation, an explanation, an example, or a series. It is also often used after the salutation of a business letter.

Dash (-): There are two kinds of dashes. These are the endash and the emdash. An endash is a symbol (-) is used in writing and printing to connect number or to connect element of compound adjectives, such as 1880-1945 or Lagos-Abuja trains. However, the emdash has more complicated grammatical use. It is used to:-

1. indicate a break in thought or sentence structure.

2. introduce a phrase added for emphasis, definition or explanation.

3. separate two clauses

A hyphen (-): It is the same symbol as the endash. It is used between parts of a compound word or name or between syllables of a word especially when divided at the end of a line of text. e.g. Mrs. Adekola-Adefesobi (compound word) back-to-back.

Parentheses (0): They are curved notations used to contain further thoughts or qualifying remarks. However, parentheses can be replaced by commas without changing the meaning in most cases. John and Jane (who were actually brothers and sisters) both have red bags.

Brackets are the squared off notation ([ ] $]$ used for technical explanation e.g. dictionary uses them for definitions.

Braces ( \{\}$)$ are used to contain two or more lines of text or listed items to show that they are considered as a unit they are seen in computer programming to show what should be contained in the same lines.

Apostrophe ('): It is used to indicate the omission of a letter or letters from a word, the possessive case, or the plurals of lower case letters.

1. Omission of letters - Nat'l - national

2. Possessive case - Kemi's bag

3. Plural for lower case letters - the students were told to mind their p's and g's.

Quotation mark (“"): It is a pair of punctuation mark used primarily to mark the beginning and end of a passage attributed to another and repeated word for word. It is also used to indicate meanings and unusual or dubious status of a word. Single quotation mark (' ') is used most frequently for quotes within quotes.

Ellipses mark (...): it is generally represented by three periods (...). Although, it is occasionally demonstrated with three asterisks $(* * *)$. They are used in writing or printing to indicate an omission especially of letters or words. They are used within quotations to jump from one phrase to another, omitting unnecessary words that do not interfere with the meaning. Students writing research papers or newspapers quoting parts of the text will often employ ellipses to avoid copying lengthy text that is not needed.

\subsection{Differences in British and American Punctuations}

There are few differences between punctuation in British and America English. These are:

Table 1. Showing the differences between punctuation in British and America English

\begin{tabular}{cll}
\hline Punctuation & British & American \\
\hline$()$. & Full stop & A period \\
$(!)$ & An exclamation mark & An exclamation point \\
$(\{\})$ & Brackets & Parentheses \\
$([])$ & Square brackets & Brackets $)$ \\
\hline
\end{tabular}




\subsection{Learning Disability in Reading and Writing}

Disability in reading and writing involves the physical difficulties in comprehending and synthesizing information. These learning disabilities include writing and reading disorders in many words and letters. Expressive writing disability indicates a struggle of thoughts on paper.(Adenuga, 2015) Symptoms of writing and reading language learning disability revolve around the act of writing. These disabilities also include problems with neatness and consistency to write, accurately copying letters and words, spelling, consistency, writing organization and coherence, finger pointing, regression, vocalization/sub-vocalization, poor head movement, poor eye fixation, concentration/emotional disturbances, and poor visual perception.(Macauley, 2009)

\section{Research Questions}

1. Will students' with punctuation errors face problem of comprehending passages?

2. Can the punctuation errors of students' be traced to their family backgrounds?

3. Will there be significant gender effect on the students'performancein the use of punctuation marks?

4. Will the type of school contributes to students' punctuation errors?

5. Is there any significant relationship between punctuation errors and students' performance?

\section{Methodology}

This study adopted an ex-post-facto design approach. The target groups for the study were Ogun State Secondary Schools in Nigeria. The samples were drawn from four (4) geo-political zones in Ogun State of Nigeria (Ijebu, Remo, Yewa and Egba). Multi-stage stratified sampling technique was used to select five co-educational Secondary Schools from the four geo-political zones. Five schools were selected with fifty (50) Secondary Students III (SSS 3) per school totaling two hundred and fifty (250) male and female students in each of the geo-political zones. Two instruments, Errors in English Language Punctuation \{Spelling and Capitals\}(EELP), and an achievement test in English Language Punctuation \{Spelling and Capitals\}(ATELP) were used to collect data from the one thousand (1000) students who were randomly sampled as participants. The validity and reliability of the instruments were determined by trial testing. The data were subjected to Chi-square, Analysis of Variance (ANOVA) and Pearson Product Moment Correlation coefficient. The data were tested for significance at the 0.05 level.

\section{Results}

\section{RQ1: Will students' with punctuation errors face problem of comprehending passage?}

The results showed that students with punctuation errors face problem of comprehending passages. Nevertheless, the chi-square value of 173 , and statistically significant at 0.05 level. There was enough evidence to conclude that students with punctuation errors face problem of comprehending passages.

\section{RQ2: Can punctuation errors of students' be traced to their family backgrounds?}

The results showed that punctuation errors of students' can be traced to their family backgrounds. Nevertheless, the chi-square value of 148.921 was statistically significant at 0.05 level. There was enough evidence to conclude that punctuation errors of students can be traced to students' family background.

\section{RQ 3: Will there be significant gender effect on the students' performances in the use of punctuation marks?}

Gender indicated about $6 \%$ of the total variation in students' performance in punctuation $\left(r^{2}=0.006, P>0.05\right)$. This was not significant. Therefore, gender of students had no significant effect on students' performance in the use of punctuation. Also, the result of the ANOVA $F=2.075(\mathrm{p}>0.05)$ and mean square of 67.941 , and 80.920 for regression and residual respectively showed that the use of punctuation marks of secondary school students in Ogun state was not sensitive to gender.

\section{RQ 4: Will the type of school contributes to students' punctuation errors?}

The type of school students attend indicated about $9 \%$ of the total variation in their punctuation errors $\left(r^{2}=0.009\right.$, $\mathrm{P}>0.05$ ). This was not significant. Therefore, the type of school had no significant effect on students' punctuation errors. Also, the result of the ANOVA, $F=3.270(\mathrm{P}>0.05)$ and mean square of 25.67, and 7.851 for regression and residual respectively showed that punctuation errors of secondary school students in Ogun State was not sensitive to 
the type of school attended.

\section{RQ 5: Is there any significant relationship between punctuation errors and students' performance?}

The result revealed a significant relationship between punctuation errors and students' performance $(\mathrm{r}=0.452$, $\mathrm{p}<0.05)$. This implied that the mean of punctuation errors of 25.48 had a significant positive correlation with the mean of students' performance of 42.59. The observed difference was statistically significant. Hence, there was a significant relationship between punctuation errors and students' performance .

\section{Conclusion}

Reading and writing skills play very vital roles in the literacy level of a people. People who cannot read are illiterates. The paper found that wrong use of punctuation can change the context of a sentence as well as its meaning leading to ambiguity in some instances. Thus, there was a need to emphasis proper use of punctuation as a means of reducing errors of students in their reading and writing skills.

\section{Recommendations}

To remediate this situation, the following recommendations should be taken into consideration:

1. Teachers should concentrate more on the use of comma, colon and semi colon that seem to be the major problematic areas of the punctuation marks.

2. Efforts should be made to revitalize use of punctuation marks in reading and writing skills

3. Greater attention should be paid to reading and writing comprehension as well as punctuation marks in the English Language curriculum at all levels of education.

4. Reading and writing as well as punctuation marks should be taught as a separate and compulsory course beginning from the primary to the tertiary institutions.

\section{References}

Adekola, B. O. (2011). Perceived Causes of Poor Performances of Secondary School Students in English Language Internal Examinations in Ogun State. International Journal of Multi-disciplinary Studies and Sports Research, 1, $234-238$.

Adekola, B.O. (2009). Some Psycho-Educational Predictors of Students' Performance in English Grammar and Comprehension in Ogun State Senior Secondary Schools. Unpublished Ph.D. Degree Thesis, Olabisi Onabanjo University.

Adenuga, T. (2015). Receptive Skill as Strategy for improving Secondary School Students' Word Pronunciation and Dictation. Unpublished Ph.D. Degree Thesis, Olabisi Onabanjo University.

Awodele, Y.O. (2003). Evaluation of Written English: A case of Senior Secondary Year Three Students in Ibadan. Journal of Educational Focus, 4, 81-92.

Jiboku, O. (2003). Relationship Between Students' Socioeconomic Background and Performance in Comprehensive Reading. Journal of Educational Focus, 4, 93-99.

Macauley, C. O. (2009). A Brief Study and Analysis of Reading Problems in School Literacy and Reading. International Journal on Language Studies, 2(1).

Oladunjoye, S.A.O. (2008). Stakeholders' Assessment of Comprehension Programme in the Nigerian JSS English Textbooks. Journal of Curriculum Studies, 15(1), 68-76.

Otenaike, A. I. (2005). Teaching, Reading Comprehension and Summary at the Secondary School Level. In A. V. Jibowo (Ed.), Language Teaching: A Book of Reading, Ibadan: Bounty Press Ltd.

\section{INTERNET SOURCES}


1. grammar.yourdictionary.com

2. library.iated.org

3. www.hrmars.com

4. good-choise.com

5. en.wikipedia.org

6. www.readingassessment.info

7. tattookittenpoems.com

8. www.ejournalofscience.org

9. www.mediamates.biz

10. iurban.org

11. asha.org

12. www.journalsbank.com

13. Ariani, Mohsen Ghasemi, and Narjes Ghafournia. "The Relationship between Socio-Economic Status, General Language Learning Outcome, and Beliefs about Language Learning", International Education Studies, 2016.

14. Multiple Perspectives on Difficulties in Learning Literacy and Numeracy, 2011.

15. www.slideshare.net

16. www.xsignia.com 